\title{
HUBUNGAN ANTARA CENDAWAN MIKORIZA ARBUSKULA INDIGENEOUS DAN SIFAT KIMIA TANAH DI LAHAN KRITIS TANJUNG ALAI, SUMATERA BARAT
}

\author{
Muzakkir \\ A gricultural Polytechnic Andalas University \\ email: azaki_ir@yahoo.co.id
}

\begin{abstract}
Critical land is land that has lost its function as an agro-ecosystem. The main problems faced in using critical land for agriculture are: 1) acidic soil reaction, 2) high amount of $\mathrm{Al}$ ions that can bind phosphorus, and 3) low organic matter content. Some treatment had been tried to improve soil chemical properties, but the result obtained is not optimal. Therefore, it is necessary to do biological improvement by utilizing indigeneous Arbuscular Mycorrhizal Fungi (AMF). Research on the relationship between Indigeneous Arbuscular Mycorrhizal Fungi and some chemical properties of degraded land have been carried out at the Laboratory of Soil Science and Microbiology Department, Faculty of Agriculture, Andalas University ( UNAND). This study was aimed to determine the relationship between the number and types of AMF with some chemical properties of critical land in Tanjung Alai Solok, West Sumatra, as well as to study the relationship between the number and types of AMF with some soil chemical properties using Pearson correlation analysis. The results showed that: the number and types of AMF is closely related to $\mathrm{pH}, \mathrm{P}$, and organic $\mathrm{C}$, with a pattern of positive relationships (unidirectional), while Al-dd soil showed negative correlation with the number and types of AMF.
\end{abstract}

Keywords: critical land, AM F, soil chemical properties

\section{PENDAHULUAN}

Luas lahan kritis bertambah terus seiring dengan peningkatan jumlah penduduk. Data tahun 2005 menunjukkan bahwa luas lahan kritis di Indonesia telah mencapai \pm 25 juta hektar (Direktorat Jenderal Pengelolaan Lahan dan Air Departemen Pertanian, 2007). Menteri Kehutanan M.S Kaban dalam harian tempo tahun 2009 menyatakan luas lahan kritis di seluruh Indonesia mencapai 30 juta hektar. Di Sumatera Barat luas lahan kritis mencapai 1.275.190,90 hektar. Dari luasan tersebut 166.587,88 hektar terhampar di Kabupaten Solok (BP DAS Agam Kuantan, 2008 dalam Amrizal Saidi, 2010). Pemanfaatan lahan kritis untuk pertanian terkendala oleh; 1) reaksi tanahnya masam (pH rendah), 2) miskin unsur hara ,2) banyaknya ion Al yang dapat mengikat fosfor, 3) kandungan bahan organik rendah (Nurhajati Hakim, 1996).
Untuk mengatasi masalah ini cara yang efektif dan bersahabat dengan lingkungan adalah penerapan bioteknologi seperti pemanfaatan Arbuscular Michorrhizal Fungi (AMF) indigenus.

Pengkajian tentang hubungan antara jumlah dan jenis AMF pada rizosfer jarak pagar yang berbeda kesuburan tanahnya merupakan hal penting dilakukan, karena selain untuk memperoleh informasi tentang jenis dan jumlah populasi AMF di ekosistemnya, juga dalam rangka memperoleh isolat AMF efektif. Hanya saja kegiatan penelitian yang berkaitan dengan hubungan antara jumlah dan jenis AMF dengan beberapa sifat kimia tanah di rizosfir jarak pagar (Jatropha curcas L.) belum ada.

Penelitian ini bertujuan untuk mengetahui hubungan antara jumlah dan jenis AMF dengan beberapa sifat kimia tanah lahan kritis Tanjung Alai Solok Sumatera Barat. Hasil penelitian dapat 
digunakan sebagai informasi awal mengenai keberadaan AMF secara alami di rizosfer jarak pagar pada lahan kritis Tanjung Alai Solok Sumatera Barat.

\section{BAHAN DAN METODA}

Penelitian dilakukan selama 3 bulan di laboratorium Mikrobiologi Jurusan Ilmu Tanah dan Hama Penyakit Fakultas Pertanian Unand. Sampel tanah berasal dari rizosfir tanaman jarak pagar pada lahan kritis Tanjung Alai Solok Sumatera Barat.

Jumlah dan jenis AMF indigenus diamati pada rizosfir tanaman jarak pagar yang tumbuh pada lahan kritis. Sampel tanah dan akar, diambil disekeliling tanaman jarak pagar pada jarak $20-50 \mathrm{~cm}$ dari pangkal batang dengan kedalaman $0-30 \mathrm{~cm}$. Sampel tanah yang diambil dianalisis sifat kimianya diantaranya; $\mathrm{pH}$ tanah, C-organik, $\mathrm{N}$ total, $\mathrm{P}$ tersedia, $\mathrm{K}$ dan $\mathrm{Al}-\mathrm{dd}$.

Ekstraksi dan identifikasi jumlah dan jenis spora cendawan mikoriza arbuskula digunakan teknik tuang saring dan dilanjutkan dengan teknik sentrifugasi dari Brundrett et al, (1996). Pembuatan preparat spora menggunakan bahan pewarna Melzer $S$ dan pengawet PVLG. Karakteristik berbagai isolat mikoriza di identifikasi berdasarkan (Schenck dan Peres, 1990, Invam, 2003).

Data yang dikumpulkan diperoleh dalam kegiatan ekstraksi dan identifikasi spora berupa jumlah dan jenis, cendawan Mikoriza Arbuskula serta analisis kimia tana. Untuk melihat hubungan antara jumlah dan jenis AMF dengan beberapa sifat kimia tanah menggunakan analisis korelasi Pearson (Steel dan Torrie, 1993).

\section{HASIL DAN PEMBAHASAN}

Sifat kimia pada lahan kritis dalam penelitian ini pH H2O (1:1) 4,4 - 5,5 (sangat masam- masam), $\mathrm{P}$ tersedia 2,40 ppm - 5,53 ppm (sangat rendah sampai rendah), Al-dd berkisar dari 2,40 - 4,28 me/100 g tanah, sedangkan C Organik rendah sampai sedang (1,31 - 2,64 persen). Sifat kimia tanah ini secara tidak langsung akan berhubungan dengan jumlah dan jenis AMF.
Berdasarkan hasil uji korelasi antara beberapa sifat kimia tanah dengan jumlah dan jenis AMF diperoleh hasil seperti pada Tabel 1.

Tabel 1 menunjukkan bahwa peubah yang berkorelasi sangat nyata dan pola hubungangannya positif dengan jumlah dan jenis AMF adalah $\mathrm{pH}, \mathrm{P}$, dan C-Organik. Pola hubungan positif antara jumlah dan jenis AMF dengan $\mathrm{pH}$ tanah pada Gambar 1, dengan $\mathrm{P}$ Gambar 2, dengan C-organik Gambar 3.

Dari Gambar 1 terlihat bahwa jumlah individu AMF angka koefisen korelasi $+0,754^{* *}$, sedangkan jumlah jenis $\mathrm{AMF}+0,697^{* *}$. Ini menunjukkan hubungan sangat erat antara $\mathrm{pH}$ dengan jumlah individu AMF dan jumlah jenis AMF. Koefisien korelasinya bertanda positif artinya hubungan antara $\mathrm{pH}$ tanah dengan jumlah individu dan jumlah jenis AMF searah, sehingga pada kisaran $\mathrm{pH} \mathrm{4,4-5,5}$ maka jumlah dan jenis AMF semakin banyak.

Perubahan $\mathrm{pH}$ rizosfir tanah mempunyai konsekuensi langsung terhadap kelarutan Al dalam tanah (Gahoonia, 1993). Faktor pH tanah yang paling penting kontribusinya terhadap potensial hasil yang rendah adalah defisiensi kalsium $(\mathrm{Ca})$ dan keracunan Aluminium (Al) (Adam dan Moore, 1983).

Dari Gambar 2 terlihat bahwa angka koefisien korelasi $+0,760^{* *}$ dan $+0,791^{* *}$ menunjukkan bahwa terdapat hubungan sanat erat antara jumlah dan jenis AMF dengan P. Koefisien korelasinya bertanda positif artinya hubungan $\mathrm{P}$ tanah dengan jumlah dan AMF searah, sehingga semakin tinggi $\mathrm{P}$ (mulai 2,56 sampai 5,94 ppm ) maka jumlah dan jenis AMF semakin banyak.

Dari Gambar 3 terlihat bahwa angka koefisen korelasi $0,650^{* *}$ dan $0,619^{* *}$ menunjukkan bahwa terdapat hubungan erat antara jumlah dan jenis AMF dengan COrganik tanah.Koefisien korelasinya bertanda positif artinya hubungan C-organik tanah dengan jumlah dan AMF searah, 
Tabel 1. Korelasi antara jumlah spora dan jumlah jenis AMF dengan beberapa sifak kimia tanah lahan kritis Tanjung Alai Sumbar

\begin{tabular}{lcccc}
\hline Sifat kimia tanah & \multicolumn{2}{c}{$\begin{array}{c}\text { Jumlah spora } \\
\text { (Individu) AMF }\end{array}$} & Jumlah jenis AMF \\
& $\begin{array}{c}\text { Nilai korelasi } \\
(\mathrm{r})\end{array}$ & P-value & $\begin{array}{c}\text { Nilai korelasi } \\
(\mathrm{r})\end{array}$ & P-value \\
\hline $\mathrm{pH}$ & $+0,754(* *)$ & 0,000 & $+0,697\left(^{* *}\right)$ & 0,000 \\
$\mathrm{P}$ & $+0,760(* *)$ & 0,000 & $+0,791\left(^{* *}\right)$ & 0,000 \\
$\mathrm{Al}-\mathrm{dd}$ & $-0,768(* *)$ & 0,000 & $-0,833\left(^{* *}\right)$ & 0,000 \\
$\mathrm{C}-$ org & $+0,650(* *)$ & 0,003 & $+0,619\left(^{* *}\right)$ & 0,006 \\
\hline
\end{tabular}

* ) korelasi nyata pada tarap 0.05

**) korelasi sangat nyata pada taraf 0.01 .

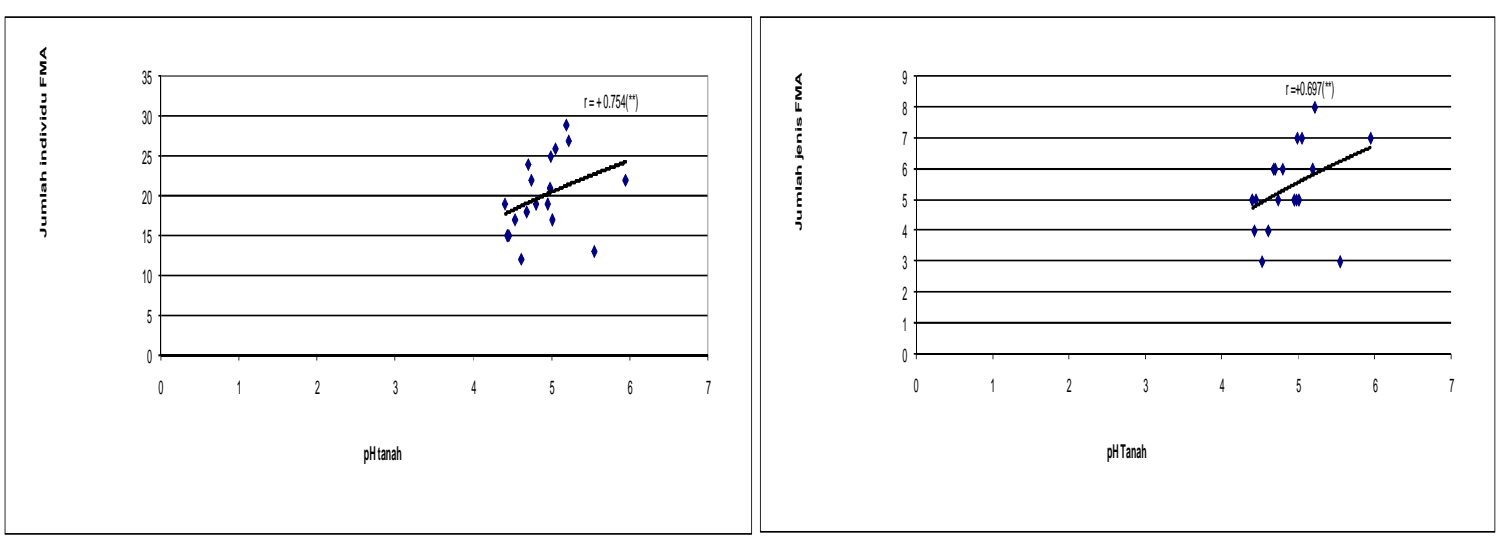

Gambar 1. Hubungan antara $\mathrm{pH}$ tanah dengan jumlah dan jenis AMF di lahan kritis
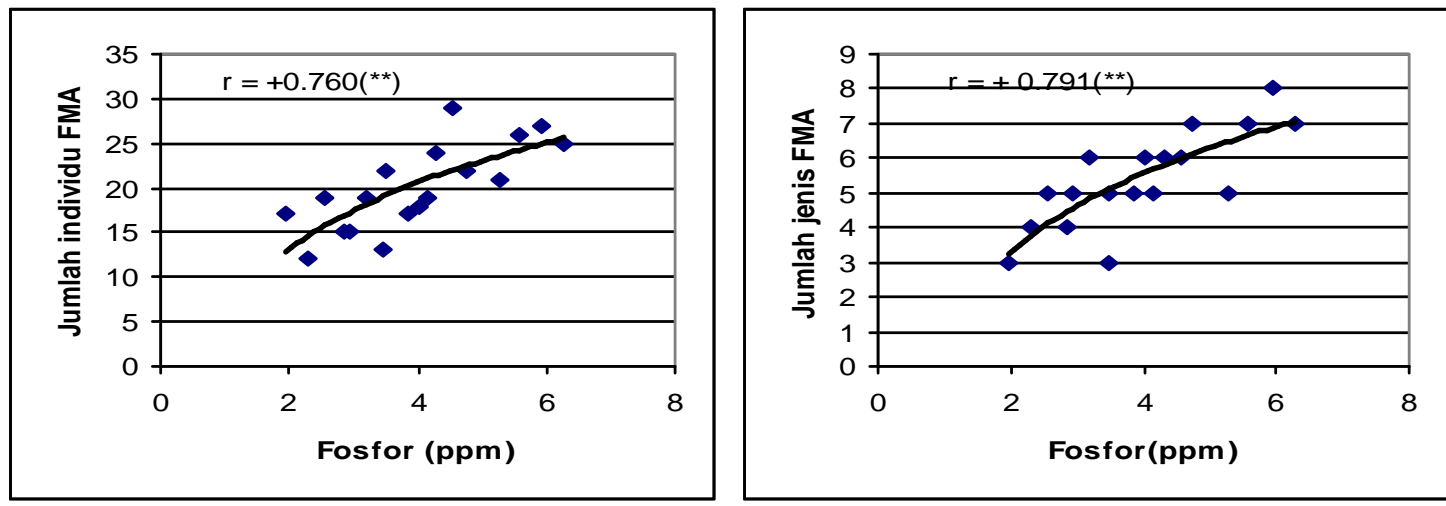

Gambar 2. Hubungan antara fosfor tanah dengan jumlah dan jenis AMF di lahan kritis
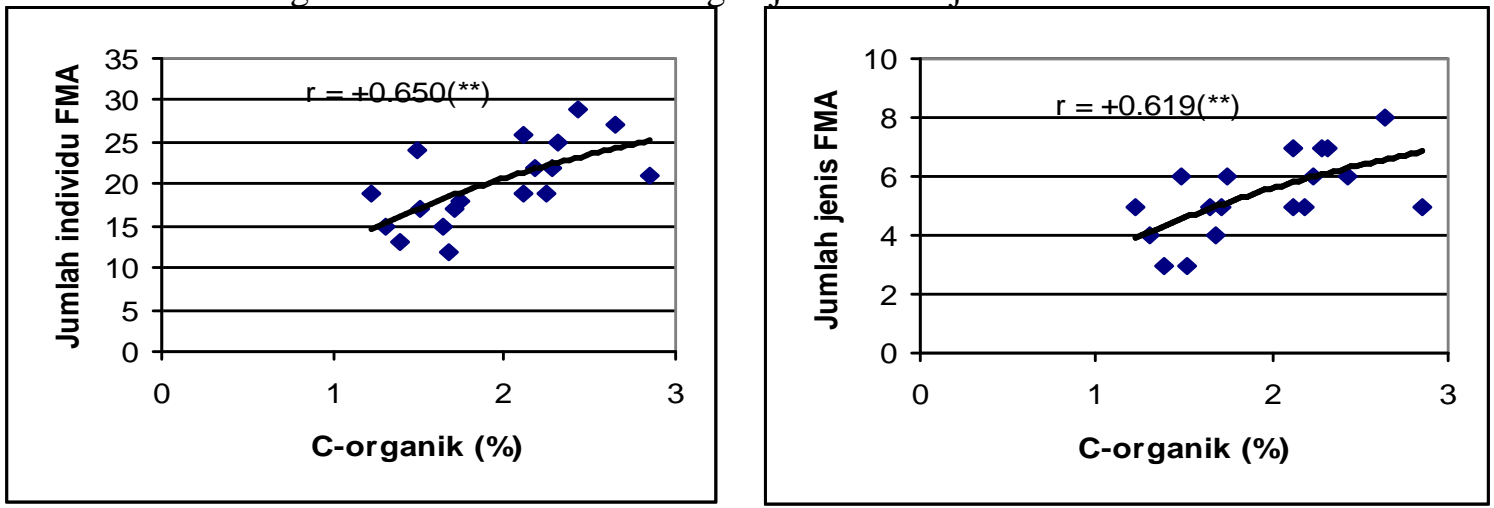

Gambar 3. Hubungan antara C-organik tanah dengan jumlah dan jenis AMF di lahan kritis 

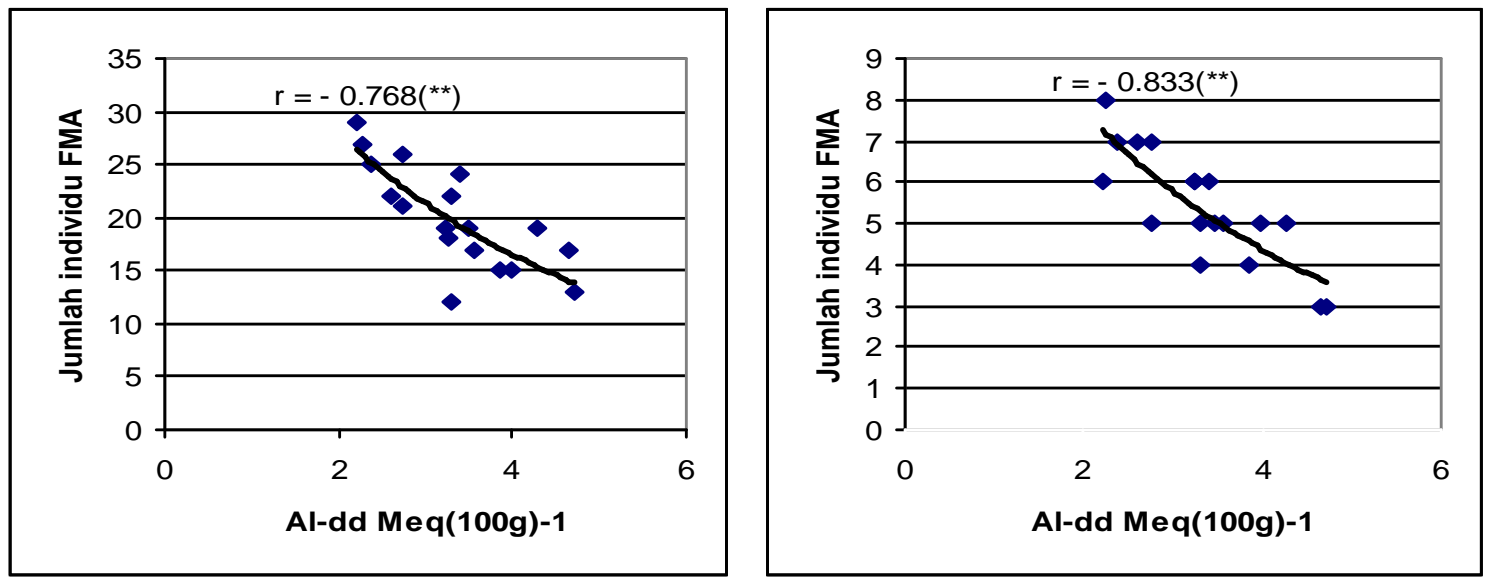

Gambar 4. Hubungan antara Al- dd tanah dengan jumlah dan jenis AMF di lahan kritis

sehingga semakin tinggi C-organik mulai 1,23 sampai $2,85 \%$, maka jumlah dan jenis AMF semakin banyak.

Secara umum Gambar diatas menunjukkan bahwa terdapat hubungan yang sangat erat antara jumlah dan jenis AMF dengan $\mathrm{pH}, \mathrm{P}$, dan $\mathrm{C}$ organik, juga pola hubungannya searah sehingga jika $\mathrm{pH}, \mathrm{P}$, dan C-organik meningkat, maka jumlah dan jenis AMF akan mengalami peningkatan. Hal ini disebabkan karena $\mathrm{pH}$ menentukan mudah tidaknya unsur hara diserap tanaman termasuk unsur $\mathrm{P}$, dimana $P$ berfungsi untuk pembelahan sel, membantu transfer energi dalam kegiatan metabolisme, sehingga pertumbuhan tanaman baik, akhirnya membantu perkembangan AMF. $\mathrm{C}$ organik dapat menjamin terjadinya mineralisasi yang hasilnya dapat menyediakan unsur hara bagi simbiosis AMF dengan tanaman.

Joner dan Jakobsen (1995) mengemukakan bahwa bahan organik dapat menginduksi pertumbuhan hifa AMF. Peubah yang berkorelasi sangat nyata dan pola hubungangannya negatif dengan jumlah dan jenis AMF adalah Aldd (Gambar 4)

Dari Gambar 4 terlihat bahwa angka koefisen korelasi $0,768^{* *}$ dan $0,833^{* *}$ menunjukkan bahwa terdapat hubungan erat antara jumlah dan jenis AMF dengan Al-dd tanah. Koefisien korelasinya bertanda negatif artinya hubungan Al-dd tanah dengan jumlah dan AMF tidak searah, sehingga semakin tinggi Aldd tanah mulai 1,23 sampai $2,85 \%$, maka jumlah dan jenis AMF semakin sedikit.

$\mathrm{Hal}$ ini disebabkan $\mathrm{Al}$ menghambat perkembangan akar (Foy, 1984). Dengan demikian sistem perakaran terbatas, sehingga akar tidak dapat memanfaatkan air dan unsur hara yang tersimpan pada subsoil. Akibatnya tanaman mudah mengalami cekaman air, pertumbuhannya terhambat dan biomas serta hasil yang diperoleh rendah. Juga $\mathrm{Al}$ dapat menfiksasi $\mathrm{P}$ pada akar tanaman dimana Al-P dalam protoplasman dan inti sel pada sel korteks akan mengakibatkan hambatan translokasi $\mathrm{P}$ keseluruh bagian tanaman termasuk ke AMF. Proses ini menghambat pembelahan sel, dan proses metabolesme sehingga pertumbuhan tanaman terhambat, akibatnya AMF yang bersimbiosis dengannya akan terhambat perkembangannya. Disamping itu, Al menghambat serapan $\mathrm{Ca}$ dan $\mathrm{Mg}$ serta translokasinya di tanaman. Keadaan ini menyebabkan ketidakseimbangan hara dalam tanaman yang akhirnya menghambat perkembangan tanaman. 


\section{KESIMPULAN DAN SARAN}

Kesimpulan

1. Hubungan antara jumlah dan jenis AMF dengan $\mathrm{pH}, \mathrm{P}$, dan $\mathrm{C}$ organik sangat erat, dengan pola hubungan yang searah sehingga jika $\mathrm{pH}, \mathrm{P}$, dan $\mathrm{C}$-organik meningkat, maka jumlah dan jenis AMF akan mengalami peningkatan. Terdapat hubungan erat antara jumlah dan jenis AMF dengan Al-dd tanah, dimana hubungannya tidak searah, sehingga semakin tinggi Al-dd tanah mulai 1,23 sampai 2,85\%, maka jumlah dan jenis AMF semakin sedikit.

Saran

Dari berbagai jenis isolat AMF yang diperoleh dalam penelitian ini perlu diteliti jenis mana yang berpotensi dijadikan isolat AMF spesifik jarak pagar.

\section{DAFTAR PUSTAKA}

Adam, F. and B.L. Moore. 1983. Chemical factors affecting root growth in subsoil horizons of Coastal Plain Soils. Soil Sci. Soc. Am. J. 47 : 99102.

Brundret. M., N. Bougher, B. Dell, T. Grove, and Malajezuk. 1994. Working with Mycorrhizas in Forestry and Agriculture ACIAR Monograph. ACIAR. Canberra.

Clark, RB.,1997. Arbuscular mycorrhizal adaptation, spora germination, root colonization, and host plant growth and mineral acquisition at low $\mathrm{pH}$. Plant Soil. 192, 15-22

Departemen Pertanian., 1983. Pedoman pengenalan berbagai jenis gulma penting pada tanaman perkebunan. Departemen Pertanian. Direktorat Jenderal Perkebunan. Jakarta, 115 hal.

Direktorat Pengelolaan Lahan dan Air Departemen Pertanian, 2007. Pedoman teknis pengembangan usaha tani pertanian terpadu. http://www.google.com. Nopember 2007.

Gahoonia Tara Singh. 1993. Influence of root-induce $\mathrm{pH}$ on the solubility of soil aluminum in the rhizosphere. Plant and Soil. 149, 289-291.
Hakim N, 1996. Teknologi Perbaikan Kesuburan Tanah Di Lahan Kritis. Lokakarya Orientasi Penerapan Teknologi Pertanian Untuk Pencegahan dan Perbaikan Lahan Kritis. Diselnggarakan Bappeda Tingkat I Sumbar. 23 hal.

Invam 2003. Internatinal culture colection of arbuscular and vesicular mycorrhizal fungi.

http://Invam.caf.wvu.edu/mycinfo/Taxonomy/classification.htm. 18 Agustus, 2003.

Schenck, N.C. and Y vone Peres. 1990. Manual for identification of mycorrhizal fungi. Published by Synergitec Publications. Gainesville USA. Third Edition, 286 hal.

Steel, R.G.D. dan J.H. Torrie., 1993. Prinsip dan Prosedure statistika. P.T Gramedia Pustaka Utama, Jakarta. 